\title{
Effect of Schisandra Chinensis Baill Distilled by Ethanol on Ageing Mice Model Induced by D-galactose
}

\author{
Mingsan Miao, Yan Li, Tan Wang \\ Henan College of Traditional Chinese Medicine. Henan Zhengzhou.450008.China
}

\begin{abstract}
Objective: To observe the effect of Schisandra Chinensis Baill distilled by ethanol on brain organization in aged mice model induced by D-galactose. Method: Injecting 5\% D-galactose saline solution in neck back to the subcutaneous of mice to make the laneuria mice model for 40 days. From the 11th day,respectively fill the mice with big,small dosage of Schisandra Chinensis Baill distilled by ethanol、 Naokangling troche and the same dosage of saline everyday. The other one was set up the blank comparing group which hyodermicing saline in the scruff. To the end of model last, decapitated brain of mice,readmission $1 / 2$ of the brain fastenned by formalin, taking $1 / 2$ of the remaining of the brain fastnened by Glutaraldehyde and observed by organization pathology and electron microscope. Results: Compared with the model group, big、 small dosage of Schisandra Chinensis Baill distilled by ethanol groups could both improve the nerve cell, and shows some relativity to dosage. Conclusion: Schisandra Chinensis Baill distilled by ethanol could improve pallium nerve cell, pectin cell and hippocampi nerve cell of mice
\end{abstract}

KEYWORD: Schisandra Chinensis Baill distilled by ethanol; D-galactose; laneuria; brain organization.

\section{GENERAL INSTRUCTIONS}

With increasing aging of the elderly, brain neurotransmitters and neurotransmitter receptors in certain brain regions of varying degrees of reduction has become a common phenomenon, neurotransmitters and brain cells to protect against damaging factors of abuse, one of which is one of the important ways to give play to the role of puzzle. Schisandra warm Pickle, lung, kidney, heart, sweating with fluid, astringent fine diarrhea, Anshen effect. Modern research shows that Schisandra has a good role in the regulation of central nervous system pharmacology, sedative, hypnotic, etc., preliminary studies show Polysaccharide [1] has antioxidant effect. To further explore the pharmacological characteristics of Schisandra chinensis, the purpose of this study was to observe the effects of the alcohol extract on D- galactose induced brain aging model mice brain tissue, in order to find out more about the clinical effect of Schisandra chinensis.

\section{MATERIALS}

\subsection{Animals}

KM male mice, whose weight were $18 \sim 21 \mathrm{~g}$, were supplied by the Experimental Animal Center of
Henan Medical Experimental Animal Center (Animal permit number: yu NO.0038)

\subsection{Drugs and reagents}

Schisandra, Purchased from Henan Province, medicine company,for Magnoliaceae Schisandra Schisandra Chinensis Baill dried ripe fruit; Schizandrol mention parts, made of coarse particles Schisandra dry, take $1000 \mathrm{~g}$, respectively, eight times the amount of $95 \%, 95 \%$ ethanol extract two times the combined alcohol extract twice, waving alcohol, concentration caused by dry, too extract $298.2 \mathrm{~g}$, extract equivalent per gram of crude drug 3.34g; Kangnaoling, Liaoning Tianlong Pharmaceutical Co, lot 20030804, specifications $0.363 \mathrm{~g} /$ piece ; $95 \%$ ethanol ( medical grade ); D- galactose, Shanghai Reagent Factory, batch number 20030809; Formaldehyde, Shanghai Solvent Plant, Lot 20030417; 25\% glutaraldehyde, Shantou City, Guangdong West Long Chemical, lot 0307121.

\subsection{Instruments}

Microscopes, electron microscopy. 


\section{METHODS}

\subsection{Animal grouping}

Take about $18 \sim 21 \mathrm{~g}$ of 50 mice, half male and half female, were randomly divided into 5 groups (male and female the cage), were randomly divided into the blank group (BG), model group (MG), Kangnaoling group and alcohol extracts of Schisandra large and small dose groups, which can also be called as the alcohol extracts of Schisandra in LS and SS, respectively.

\subsection{D-galactose induced aging model construction [2-5]}

Model group, Kangnaoling group , large doses of alcohol extracts of the group, a small dose of alcohol extracts of group daily subcutaneous injection $5 \%$ D- galactose saline solution $0.5 \mathrm{~mL} /$ $20 \mathrm{~g}(1.25 \mathrm{~g} / \mathrm{kg})$, the control group was injected the same dose of saline $0.5 \mathrm{~mL} / 20 \mathrm{~g}$. Every four days a weight meter, said adjusted dose, continuously to 40 days D- galactose. The first 11 days from the beginning, were fed large and small doses of alcohol extracts of Schisandra suspension $(0.4 \mathrm{~g} / \mathrm{kg}$, $0.2 \mathrm{~g} / \mathrm{kg}$, taking the extract with $0.5 \% \mathrm{CMC}$ dubbed $20 \mathrm{mg} / \mathrm{ml}, 10 \mathrm{mg} / \mathrm{ml}, 0.2 \mathrm{ml} / 10 \mathrm{~g}$ ), Kangnaoling slice suspension $(0.7 \mathrm{~g} / \mathrm{kg}$, with a $0.5 \%$ CMC dubbed $35 \mathrm{mg} / \mathrm{ml}, 0.2 \mathrm{ml} / 10 \mathrm{~g}$ ) daily. Blank control group and model group was given the same volume of saline freely feeding, drinking pure water.

\subsection{Determination of biochemical markers}

To modeling after the end of the mice brains were removed, get a brain half with $10 \%$ formalin-fixed, the remaining half of the brain to do with glutaraldehyde-fixed tissue pathology and electron microscopy. Cortex cells and glial cells, nerve cells in the hippocampus part of the impact observed schizandrol mention parts of mouse neural.

\section{METHODS STATISTICAL ANALYSIS}

Number figures consecutively in the order in which reference is made to them in the text, making no dis Data were analyzed using windows statistical software SPSS 13.0. The differences of measurement data between groups were analyzed using ANOVA.

\section{RESULTS}

Cortex cells and glial cells, nerve cells in the hippocampus part of the impact observed schizandrol mention parts of mouse neural.

By experimental methods of nerve cells and glial cells, nerve cells in the hippocampus part of the cerebral cortex of mice in each group were observed, the results are shown in Table 1 .

Table 1. experimental groups cortical neurons and glial cells in mice comparing density $(\bar{x} \pm s)$

\begin{tabular}{|c|c|c|c|c|c|c|}
\hline group & $\mathrm{n}$ & Dose $(\mathrm{g} / \mathrm{kg})$ & Observations & $\begin{array}{c}\text { Cortical neurons } \\
(\mathrm{Vv})\end{array}$ & $\begin{array}{c}\text { Glial cells } \\
(\mathrm{Vv})\end{array}$ & $\begin{array}{c}\text { Hippocampal neurons } \\
(\mathrm{Vv})\end{array}$ \\
\hline $\mathrm{BG}$ & 10 & & 30 & $36.42 \pm 12.36^{* *}$ & $6.7 \pm 0.3^{* *}$ & $13.6 \pm 2.6^{* *}$ \\
\hline $\mathrm{MG}$ & 10 & & 30 & $11.78 \pm 21.43$ & $1.7 \pm 0.6$ & $6.3 \pm 2.2$ \\
\hline Kangnaoling group & 10 & 0.7 & 30 & $20.19 \pm 28.11$ & $3.4 \pm 0.8^{* *}$ & $8.1 \pm 2.8^{*}$ \\
\hline $\begin{array}{c}\text { the alcohol extracts of } \\
\text { Schisandra in LS }\end{array}$ & 10 & 0.4 & 30 & $24.36 \pm 18.32^{*}$ & $4.6 \pm 0.8^{* *}$ & $8.7 \pm 2.9 * *$ \\
\hline $\begin{array}{c}\text { the alcohol extracts of } \\
\text { Schisandra in SS }\end{array}$ & 10 & 0.2 & 30 & $29.78 \pm 16.41^{* *}$ & $4.8 \pm 0.4^{* *}$ & $9.8 \pm 2.3 * *$ \\
\hline
\end{tabular}

***Compared with the model group, said $\mathrm{P}<0.01$

*Compared with the model group, said $\mathrm{P}<0.05$

As can be seen from the table, compared with the control group, cells, glial cells and hippocampal neurons in the cerebral cortex nerve $\mathrm{Vv}$ model mice were significantly reduced, indicating that brain aging model made successful; Ministry of model group and hippocampus brain cells damage main pathological changes in the nerve cells into nerve cells volume shrinking, reducing cytoplasm, vacuolar changes occur within the cytoplasm; dendrites, axons decreased or disappeared; significantly reduced glial cells. Compared with the model group, Kangnaoling groups, large and small doses of alcohol extract of Schisandra parts group were improved in mice cerebral cortex neurons and glial cells, nerve cells in the hippocampus part, and with a certain degree of dose -related sex.

\section{DISCUSSION}

D-gal aging model $\mathrm{D}$ - galactose principle is triggered by non-enzymatic glycosylation reaction in the body, damage the normal physiological function of biological macromolecules, and the reaction products of advanced glycation end products (AGEs) -induced free radicals injury, further 
amplifying the effect of non- enzymatic glycation caused. Mice injected D- long- galactose, can cause systemic metabolic disorders, resulting in organ function decline. Performance of brain cell membrane damage and other phenomena, these changes with aging in mice similar[6]. Aging is a degenerative brain changes occur in the brain during aging body, meanwhile, has also undergone a brain histology corresponding changes, including changes in cerebral cortical neurons recession, glial cells and neurons in hippocampal structure and function . Slow down brain aging research in recent years, Chinese medicine has achieved some success[7], the paper schizandrol extract anti- aging effects of brain related research .

Jin "Bao $\mathrm{Pu}$ "Schisandra" uniforms can rejuvenate, longevity," the record; Ming " Compendium of Materia Medica " record: Schisandra " tonic labor, it is the body Yuet -taek, eyesight " ; prompt Schisandra has a good anti-aging effect. Schisandra has been reported near the site of alcohol extract can significantly improve the learning ability of mice[8], Schisandra lignans, Sch B , Schisanhenol good antioxidant[9], have also been reported to have a good water extract of Schisandra beneficial Chi effect[10]. Our previous studies have shown that Polysaccharide have antiaging effects, for the full discovery of the pharmacological effects of Schisandra observed schizandrol mention parts of the brain aging model of pharmacological effects. In this study, microscopic observation of brain tissue in mice showed schizandrol extracts can improve cell, glial cells D- galactose degenerative changes made, model mouse cortical neurons and hippocampal nerve cells, can antagonize D - galactose pathology caused by nerve cell damage . Tip schizandrol extract sites can improve brain cell function in mouse models, while this study for clinical application of brain aging Schisandra prevention and treatment of diseases of the foundation.

\section{REFERENCES}

[1] Ma YX, Huang YX, Zhou HC, 2014, et al. Pharmacological and Clinical Research Schisandra modern Chinese medicine information, 1 (31): 125-126.

[2] Miao MS, Ma X, Zhang GW, 2010et al. Schizandrol extract brain neurotransmitter effects of aging model Chinese Journal of Gerontology in mice, 8(30): 21622163.

[3] Liu GS, Yang B, Zhang ZS, 2014. et al. Effects of resveratrol on D- galactose induced aging mice learning and memory ability and brain tissue antioxidant capacity Food Science,35 (05) : 204-207.

[4] Shi N, Su J, Yang ZB, 2014, et al. Atractylodes polysaccharide D- galactose model mice antioxidant effect Chinese Journal of New Drugs 23 (5): 577-584.

[5] Zhang YY, Wang YH, Shi Y, 2014, et al. Honeysuckle decoction D- galactose-induced aging mice antioxidant effect Journal of Zhejiang University of Traditional Chinese Medicine,38 (3): 321-326.

[6] Lei M, Zhu ZJ. 2011, Progress aging D- galactose Progress of Anatomical Sciences, 17 (1): 83-85.

[7] Gao XL, Gao FG, 2012, et al.Advances in brain aging medicine anti Hebei Medical. 18 (3): 408-410.

[8] Xu B, An Y, Shen N, 2013, et al. Schisandra alcohol extract of sodium nitrite induced memory disorders affect memory function in mice with consolidation Pharmaceutical Research, 7: 34-35.

[9] Liu L, Zhao S, Ma YQ, 2011, et al.Research Progress Schisandra antioxidant and antibacterial effects Zhongkai University of Agriculture Engineering. 24 (3): 63-66.

[10] Hao JF, Zhang HS. 2010. Schisandra research overview of the role of the central nervous system Chinese pharmacist, 13(12):1813-1815. 